\title{
Partial auricular reconstruction surgery for facial skin cancer
}

\author{
Mattie Rosi-Schumacher ${ }^{1}$, Tom Shokri ${ }^{2}$, Benjamin Bassichis ${ }^{3}$ \\ ${ }^{1}$ Department of Otolaryngology-Head and Neck Surgery, Jacobs School of Medicine and Biomedical Sciences at the University at \\ Buffalo, Buffalo, NY 14203, USA. \\ ${ }^{2}$ Department of Facial Plastic and Reconstructive Surgery, Division of Otolaryngology-Head \& Neck Surgery, The George \\ Washington University School of Medicine \& Health Sciences, Washington, DC 20052, USA. \\ ${ }^{3}$ Department of Facial Plastic Surgery, Advanced Facial Plastic Surgery Center, Dallas, TX 75254, USA.
}

Correspondence to: Dr. Tom Shokri, Department of Facial Plastic and Reconstructive Surgery, Division of Otolaryngology-Head \& Neck Surgery, The George Washington University School of Medicine \& Health Sciences, 2300 I St NW, Washington, DC 20052, USA. E-mail: tom.shokri@gmail.com

How to cite this article: Rosi-Schumacher M, Shokri T, Bassichis B. Partial auricular reconstruction surgery for facial skin cancer. Plast Aesthet Res 2022;9:11. https://dx.doi.org/10.20517/2347-9264.2021.64

Received: 15 Jun 2021 First Decision: 15 Oct 2021 Revised: 12 Dec 2021 Accepted: 21 Dec 2021 Published: 8 Feb 2022

Academic Editors: Yi-Lin Cao, Wen-Guo Cui Copy Editor: Yue-Yue Zhang Production Editor: Yue-Yue Zhang

\begin{abstract}
Auricular defects resulting from excision of cutaneous malignancies pose a challenge to the reconstructive surgeon due to the complex anatomy, convexities, and concavities of the ear. A surgeon must be familiar with analyzing defects of the ear and understand the variety of reconstructive options available with the goals of restoring function, re-establishing anatomic units, and achieving aesthetic balance. This review summarizes current methods for reconstruction of partial auricular defects resulting from neoplasm. A brief overview of ear anatomy and aesthetic relationships is also provided. Techniques for the reconstruction are classified by anatomic region: upperthird, middle-third, and lower-third defects.
\end{abstract}

Keywords: Auricular reconstruction, facial skin cancer, cutaneous malignancy, Mohs reconstructive surgery, facial plastics, reconstructive surgery, skin cancer of the ear

\section{INTRODUCTION}

Approximately $5 \%$ to $8 \%$ of all skin cancers are located on the external ear, while the helical rim is the most 
common location in over $50 \%$ of auricular skin cancers ${ }^{[1,2]}$. The ear's location and projection render it particularly susceptible to environmental exposures and ultraviolet radiation that increase the risk of developing a cutaneous malignancy. Squamous cell carcinoma is more common than basal cell carcinoma to present on the ear, and cutaneous melanoma is relatively rare ${ }^{[2-4]}$. Mohs micrographic surgery is often used to excise nonmelanoma cutaneous malignancies in this region to allow for oncologic resection with the least loss of normal tissue and form ${ }^{[5]}$. The variable outcomes resulting from this procedure require experienced reconstructive surgeons with the ability to work with defects of diverse sizes and locations.

Auricular reconstruction focuses on structure and function, restoring anatomical landmarks, and providing a cosmetic result ${ }^{[6,7]}$. Fibrocartilage provides mechanical support to the upper two-thirds of the ear, while the lower third of the ear is composed of skin over fibrofatty tissue. In addition, the loose layer of connective tissue and adipose between the skin and perichondrium present on the posteromedial surface of the auricle renders the skin more mobile and readily available for grafts and flaps for the reconstructive surgeon. This is in contrast to the anterolateral surface of the auricle, which is tightly adherent to the underlying perichondrium.

Understanding normal auricular architecture, orientation, and aesthetic relationships can assist in preoperative planning and assessment of defects. The average adult ear is 55 to $65 \mathrm{~mm}$ long and has a width of approximately $55 \%$ of its length ${ }^{[8,9]}$. Facial features provide landmarks for the ideal auricular position. The inferior point of the lobule should be at the level of the subnasale and the superior point of the upper helical rim should align with the level of the superior orbital rim or upper tarsal creas $\mathrm{e}^{[10]}$. The vertical axis of the ear is inclined 15-20 degrees posteriorly ${ }^{[11]}$. The protrusion of the auricle from the scalp should range between 1-2 cm at a 25-35 degree angle ${ }^{[9]}$. The classically described three regions of the ear have been defined by anatomic borders [Table 1]. The upper third of the ear is defined as the portion superior to the concha cymba and above the Frankfort horizontal line. The upper third of the ear represents an important functional structure for those patients who use behind-the-ear hearing aids or wear glasses. The middle third of the ear represents the space between the concha cymba and the start of the lobule. The lower third of the ear is known as the lobule and is located below the level of the intertragal notch. The vascular supply of the ear comes from branches of the superficial temporal artery and posterior auricular artery, which come together in a complex network of vessels ${ }^{[12,13]}$. Auricular tissue viability after trauma and auricular flap reconstruction is made possible by these multiple anastomoses and perforators of the superficial temporal and posterior auricular arteries ${ }^{[14]}$. The external ear receives sensory innervation from several sources ${ }^{[15]}$. The anterior auricle and tragus are innervated by the auriculotemporal nerve (Cranial Nerve V3). The inferior surface and lobule are supplied by the great auricular nerve (C2-3). The superior cranial surface of the ear is innervated by the lesser occipital nerve (C2-3). The posterior inferior external auditory canal and inferior conchal bowl are innervated by the auricular branch (Arnold's nerve) of the vagus nerve (Cranial Nerve X).

It is helpful to analyze defects of the ear by depth, layer involved, and size. If a defect is limited to the cutaneous layer, secondary healing or primary closure may be best. Tension-free closure should be achieved and may necessitate trimming of underlying helical cartilage. In regions with less skin laxity, usually the anterior or lateral surface of the ear, skin grafting represents an option for defect coverage. However, exposed cartilage without healthy overlying perichondrium will not support a skin graft, and excision should be considered. Skin grafts should be fenestrated and secured with bolsters. The remainder of more complex ear defects are commonly classified by the affected anatomical regions.

\section{DEFECTS OF THE UPPER THIRD}

Defects smaller than $1.5 \mathrm{~cm}$ can be converted to a full-thickness wedge excision and closed primarily in 
Table 1. Anatomic regions of the ear

\begin{tabular}{ll}
\hline Region of the ear & Anatomical borders \\
\hline Upper third of the ear & Superior to the concha cymba and above the Frankfort horizontal line \\
Middle third of the ear & Between the concha cymba and the start of the lobule \\
Lower third of the ear & Below the intertragal notch \\
\hline
\end{tabular}

layers ${ }^{[16]}$. Larger defects that are not amenable to wedge excision due to irregular cupping of the pinna upon primary closure can be modified to a star excision ${ }^{[17]}$. This method includes the addition of two triangular excisions in line with the antihelical fold on either side of the wedge. This modification helps to decrease tension and prevent excessive convexity or accentuated concavity [Figure 1].

A helical rim defect between 1.5 and $2 \mathrm{~cm}$ can be reconstructed using unilateral or bilateral helical chondrocutaneous advancement flaps, such as the Antia-Buch method [Figure 2] $]^{[18-21]}$. The medial skin is preserved to maintain the flap supply via the posterior arterial network. Incisions through the lateral skin and cartilage will mobilize the chondrocutaneous flaps, which can then be moved concentrically to reconstruct helical defects. Flap advancement and tension-free closure are achieved by the wide undermining of postauricular skin and, in some cases, excision of Burrow triangles for greater mobility. For larger defects, an incision at the root of the helix can also be made to advance the helix further in a V-to-Y fashion $^{[17]}$. For larger defects extending beyond the helical rim, composite grafts approximately half the size of the defect should be harvested from the contralateral ear ${ }^{[22]}$.

Defects larger than $2 \mathrm{~cm}$ can be reconstructed with a 3-stage bipedicled tube flap composed of pre- or postauricular skin [Figure 3] ${ }^{[17,19,23,24]}$. The flap is designed to be as long as the defect with a few extra millimeters to allow for attachment to the ear, and is harvested subcutaneously from hair-free skin of the mastoid area or pre-auricular skin. The anterior and posterior margins of the flap are sutured respectively to the anterior and posterior edges of the ear defect. The flap is tubed by suturing the free caudal and cephalic ends of the flap. The donor site is closed directly. The flap is left attached to its pedicles for approximately three weeks. In stage two, one pedicle is severed, and the flap is attached to the corresponding aspect of the helical defect. In stage three, after an additional 3 weeks, the second pedicle is divided, and the flap inset is completed. This repair can also be completed in two stages.

Larger defects may require the use of temporoparietal fascial flap, cartilage, and full-thickness skin grafting $^{[25,26]}$. The nasal septum, auricular conchal bowl, or rib can serve as sites for donor cartilage harvest. The temporoparietal fascial flap is pedicled on the posterior branch of the superficial temporal artery and should be interpositioned between the underlying cartilage and overlying $\operatorname{skin}^{[25]}$.

\section{DEFECTS OF THE MIDDLE THIRD}

The pedicled postauricular interpolation flap can be used to reconstruct defects of the helical rim, antihelix, or conchal bowl ${ }^{[2,27]}$. It is commonly performed as a two-stage procedure and uses the tissues donated from the non-hair-bearing temporal scalp. The auricular soft tissue defect should be defined, and parallel horizontal incisions should be marked at the superior and inferior aspect of the defect, running from the postauricular sulcus to the hair-bearing temporal scalp ${ }^{[22]}$. The flap is pedicled posteriorly and elevated in the subfascial plane, advanced, and inset over the lateral helical rim defect. The second stage, division and inset, can be performed 3 to 4 weeks later. This flap can also support underlying cartilage grafts inserted during either stage of the surgery. 

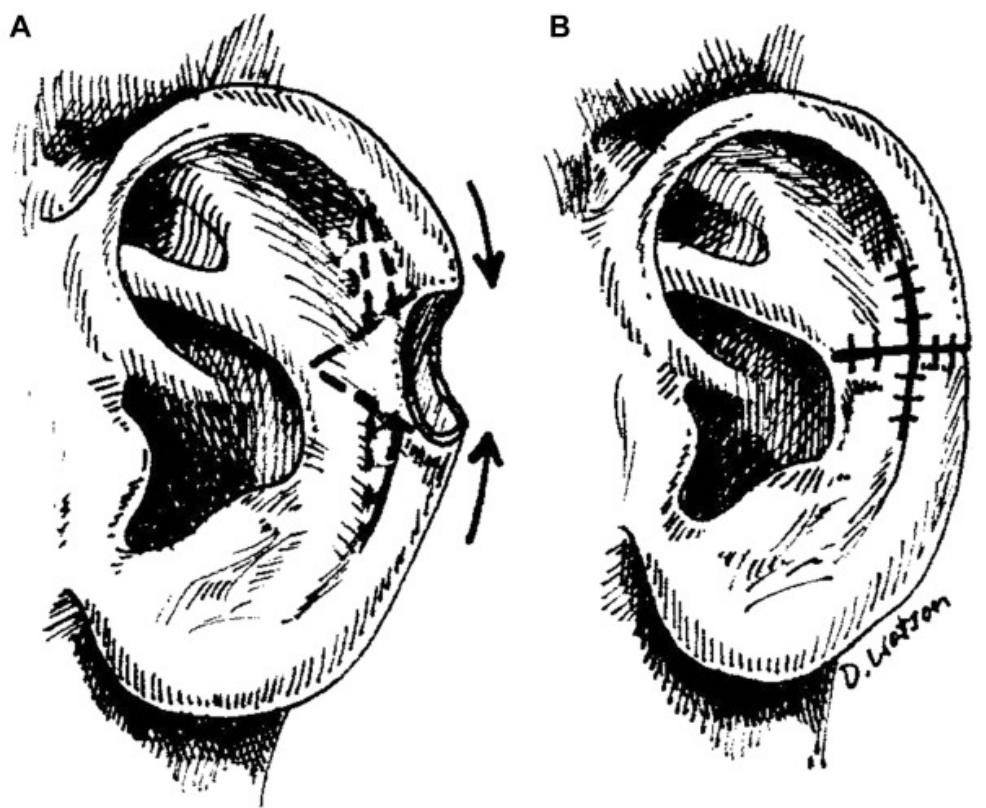

Figure 1. (A) Stellate wedge excision for advancement closure of ear defect. (B) Advancement closure following stellate excision of anterior skin and cartilage parallel to antihelical folds. (Reused with permission: Ref. ${ }^{[36]}$ ).


Figure 2. (A) Dotted line delineates planned incisions for chondrocutaneous flap. (B) Incisions along the lateral skin and cartilage are made while keeping the post-auricular skin intact in order to retain perfusion to the skin envelope. (C) Advancement closure of the chondrocutaneous flaps; note $\mathrm{V}$-to-Y advancement closure along helical root to relieve anticipated tension.

The earlobe-based advancement flap technique can also be used for the reconstruction of full-thickness helical rim defects ${ }^{[28]}$. This flap relies on the axial vessels running circumferentially along the helical rim. The surgical technique creates an axial flap with an inferiorly based arterial supply via an incision made from the defect's lower margin and carried along the scaphoid fossa. The flap is then advanced to close the defect, with mobility provided by the elasticity of the earlobe ${ }^{[28]}$. An additional triangular excision of tissue at the inferior aspect of the incision within the earlobe can allow for even further mobility of the flap for large defects. During closure, the cartilage should be reapproximated followed by closure of the anterior and posterior skin. 

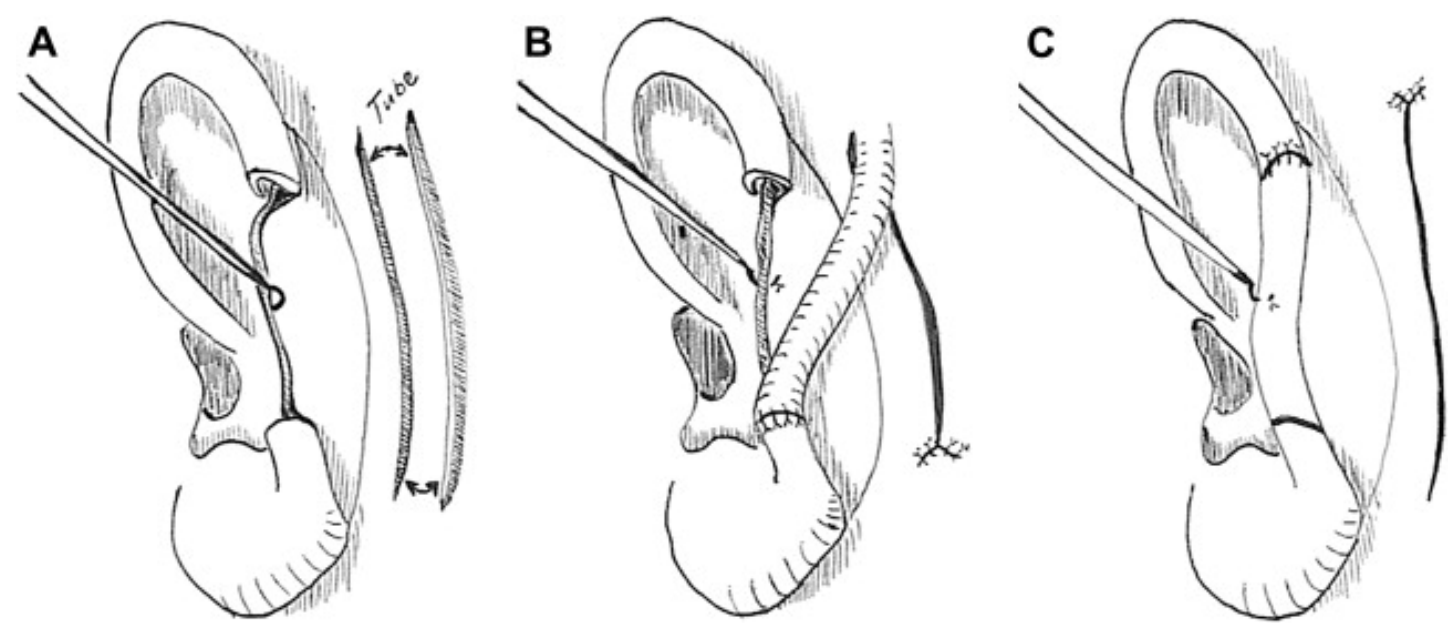

Figure 3. 3 Stage tubed bipedicled postauricular flap. (A) Post auricular skin is harvested and tubed on itself while pedicled superiorly and inferiorly. (B) At 2-3 weeks the inferior limb is transposed, leaving superior pedicle intact. (C) The superior pedicle is then divided in delayed fashion and the tubed flap is opened and inset into the auricular rim defect. (Reused with permission: Ref. ${ }^{[10]}$ ).

Single pedicled chondrocutaneous composite advancement flaps may be used to reconstruct small defects of the helical rim, while bipedicled flaps are more commonly used for defects greater than $1.5 \mathrm{~cm}^{[29]}$. The technique is similar to the above described in the reconstruction of the upper third. In reconstruction of the middle ear, the incision will begin at the antihelix or scaphoid fossa and parallel the antihelical fold ${ }^{[29]}$.

For partial-thickness defects of the conchal bowl involving the cartilage, the postauricular island "flip flop flap" or modified pull-through flap can be utilized for reconstruction ${ }^{[30-33]}$. The flap is based on the posterior auricular artery and designed over the postauricular crease, in the same size as the conchal defect ${ }^{[30]}$. The flap is raised over the pinna in a subperichondrial plane from lateral to medial stopping before the postauricular crease, at which point the portion of the flap over the mastoid is incised ${ }^{[33]}$. Depending on demands for thickness, the posterior auricular muscle can be harvested in part with the flap. Flap elevation is from posterior to anterior. Superior and inferior incisions are made to elevate the island, with preservation of the posterior auricular artery blood supply in the postauricular crease ${ }^{[31]}$. An opening in the defect through the posterior aspect of the conchal bowl is made to allow entrance of the island flap, which is transposed and anteriorly rotated 180 degrees ${ }^{[30]}$. The donor site is closed primarily with local tissue advancement.

Single stage reconstruction can also be carried out by use of the neighboring postauricular skin over a conchal cartilage framework. This method works well if there is no antihelix or superior crus defect and the defect involves less than half of the earlobe or less than $1 \mathrm{~cm}$ of the upper auricle ${ }^{[34]}$. Structural support for the reconstruction is provided by conchal cartilage or cartilage harvested from the rib. A bipedicle skin flap is created by undermining the postauricular and mastoid skin adjacent to the auricular defect, which is then shaped into a tunnel and positioned to cover the cartilaginous framework ${ }^{[34]}$.

\section{DEFECTS OF THE LOWER THIRD}

Skin defects of the lobule are subject to deformity and scar contracture if repaired with skin grafting alone. Total lobule defects should be repaired in multiple stages ${ }^{[22]}$. Ear lobe reconstruction can be accomplished using shaped conchal cartilage. A vascularized skin flap can be raised, forming a subcutaneous pocket inferior to the auricle at the location of the desired new lobule ${ }^{[26]}$. The cartilage graft is placed inside, and the inferior aspect of the existing ear is sutured to the pocket. At the second stage, the cartilage and overlying 
skin are elevated together to form the new lobule while the donor site is closed primarily ${ }^{[22]}$. If needed, skin grafts may be used for further coverage.

Another one-stage reconstructive option for earlobe defects is Gavello's procedure ${ }^{[35]}$. This technique uses the postauricular mastoid region as the flap donor site, which receives its arterial supply from the occipital branch of the posterior auricular artery ${ }^{[35]}$. A bilobed skin flap is created in the postauricular skin. First, a straight incision is made at the level of the earlobe defect and extended to twice its length. Next, a curved incision is made in the arc shape of an earlobe, beginning one centimeter inferior to the straight incision. A second curved incision is made in continuity with the first and connects the distal aspect of the straight postauricular incision. The bilobed flap is then raised by subcutaneous dissection and folded on itself at the middle point between the two curved incisions. The superior aspect of the flap is then sutured to the cut and freshened margin of the earlobe defect. The lower curved borders of the bilobed flap are sutured and form the margins of the newly reconstructed earlobe. The postauricular donor site can be closed primarily after wide undermining.

\section{COMPLICATIONS}

Complications of auricular reconstruction may include hematoma, infection, hypertrophic scarring, and poor healing. Surgeons should be careful to obtain meticulous hemostasis during all phases of the operation. The proper post-operative dressings with the use of delicate compression over the reconstructed ear may also aid in skin flap adherence. The surgeon should monitor for skin necrosis that may occur up to two weeks after surgery. It should be treated by removal of the dead tissue and subsequent coverage of the exposed cartilage with a fascial flap followed by skin graft, or other reconstructive options. Costal cartilage harvest for auricular reconstruction carries its own unique complications. Accidental penetration of the lung pleura during surgical dissection of the rib can cause a pneumothorax and should be treated accordingly with chest tube insertion. Long-term complications of auricular reconstruction may also occur, including absorption of cartilage and loss of auricular support. This is often the result of high-tension surgical closures and may require a secondary reconstructive operation.

\section{CONCLUSIONS}

The unique structure of the auricle with a complex cartilaginous framework poses an intricate challenge to the reconstructive surgeon. The ear's functions, including support of glasses and hearing aids as well as its important aesthetic relationships to the face, call for careful attention to detail when designing its reconstruction. The goals of restoring both form and function as well as achieving facial symmetry and balance are made possible through a systematic approach to reconstructive surgery. Understanding principles and techniques as well as staged methods of reconstruction will be essential to achieve these endpoints.

\section{DECLARATIONS}

\section{Authors' contributions}

Made substantial contributions to conception and design of the study, performed final editing of the document for publication: Rosi-Schumacher M, Shokri T

Provided administrative and technical support, contributed to the final editing of the document for publication: Bassichis B

\section{Availability of data and materials}

Not applicable. 


\section{Financial support and sponsorship}

None.

\section{Conflicts of interest}

All authors declared that there are no conflicts of interest.

\section{Ethical approval and consent to participate}

Not applicable.

\section{Consent for publication}

The authors obtained the copyright permission of figures.

\section{Copyright}

(c) The Author(s) 2022.

\section{REFERENCES}

1. Pless J. Carcinoma of the external ear. Scand J Plast Reconstr Surg 1976;10:147-51. DOI PubMed

2. Blake G, Wilson J. Malignant tumours of the ear and their treatment. Br J Plast Surg 1974;27:67-76. DOI PubMed

3. Sand M, Sand D, Brors D, Altmeyer P, Mann B, Bechara FG. Cutaneous lesions of the external ear. Head Face Med 2008;4:2. DOI PubMed PMC

4. Hudson D, Krige J, Strover R, King HS. Malignant melanoma of the external ear. Br J Plast Surg 1990;43:608-11. DOI PubMed

5. Ibrahim AM, Rabie AN, Borud L, Tobias AM, Lee BT, Lin SJ. Common patterns of reconstruction for Mohs defects in the head and neck. J Craniofac Surg 2014;25:87-92. DOI PubMed

6. Park SS, Hood RJ. Auricular reconstruction. Otolaryngol Clin North Am 2001;34:713-38. DOI PubMed

7. Pham TV, Early SV, Park SS. Surgery of the auricle. Facial Plast Surg 2003;19:53-74. DOI PubMed

8. Farkas LG. Anthropometry of the normal and defective ear. Clin Plast Surg 1990;17:213-21. PubMed

9. Tolleth H. Artistic anatomy, dimensions, and proportions of the external ear. Clin Plast Surg 1978;5:337-45. PubMed

10. Shonka DC Jr, Park SS. Ear defects. Facial Plast Surg Clin North Am 2009;17:429-43. DOI PubMed

11. Skiles MS, Randall P. The Aesthetics of ear placement: an experimental study. Plast Reconstr Surg 1983;72:133-8. DOI PubMed

12. Pinar YA, Ikiz ZA, Bilge O. Arterial anatomy of the auricle: its importance for reconstructive surgery. Surg Radiol Anat 2003;25:1759. DOI PubMed

13. Park C, Lineaweaver WC, Rumly TO, Buncke HJ. Arterial supply of the anterior ear. Plast Reconstr Surg 1992;90:38-44. DOI PubMed

14. Park C, Roh TS. Anatomy and embryology of the external ear and their clinical correlation. Clin Plast Surg 2002;29:155-74. DOI PubMed

15. Netter FH. Atlas of human anatomy. 6th ed. Philadelphia, PA; 2014.

16. Radonich MA, Zaher M, Bisaccia E, Scarborough D. Auricular reconstruction of helical rim defects: wedge resection revisited. Dermatol Surg 2002;28:62-5. DOI PubMed

17. Sivam SK, Taylor CB, Stallworth CL. Reconstruction of upper third auricular defects. Oper Tech Otolaryngol Neck Surg 2017;28:10513. DOI

18. Smith RM, Byrne PJ. Reconstruction of the ear. Facial Plast Surg Clin North Am 2019;27:95-104. DOI PubMed

19. Crisan D, Schneider LA, Kastler S, Scharffetter-Kochanek K, Crisan M, Veit JA. Surgical management of skin cancer and trauma involving the middle third of the auricle. J Dtsch Dermatol Ges 2018;16:694-701. DOI PubMed

20. Joshi R, Sclafani AP. The Antia-Buch chondrocutaneous advancement flap for auricular reconstruction. Ear Nose Throat $J$ 2016;95:216-7. DOI PubMed

21. Antia NH, Buch VI. Chondrocutaneous advancement flap for the marginal defect of the ear. Plast Reconstr Surg 1967:39. DOI PubMed

22. Hadlock TA, Cheney ML, Quatela V. Reconstruction of the auricle. Baker: local flaps in facial reconstruction. Philadelphia: Elsevier Saunders; 2014. p. 588-629.

23. Ellabban MG, Maamoun MI, Elsharkawi M. The bi-pedicle post-auricular tube flap for reconstruction of partial ear defects. Br J Plast Surg 2003;56:593-8. DOI PubMed

24. Ali E, Nasrin N, Azin E. Aesthetic reconstruction of the upper antihelix in external ear with banner pull-through flap. $J$ Cutan Aesthet Surg 2015;8:218-21. DOI PubMed PMC

25. Brent B, Byrd HS. Secondary ear reconstruction with cartilage grafts covered by axial, random, and free flaps of temporoparietal fascia. Plast Reconstr Surg 1983;72:141-52. DOI PubMed

26. Armin BB, Ruder RO, Azizadeh B. Partial auricular reconstruction. Semin Plast Surg 2011;25:249-56. DOI PubMed PMC

27. Pickrell BB, Hughes CD, Maricevich RS. Partial ear defects. Semin Plast Surg 2017;31:134-40. DOI PubMed PMC 
28. Zilinsky I, Cotofana S, Hammer N, et al. The arterial blood supply of the helical rim and the earlobe-based advancement flap (ELBAF): a new strategy for reconstructions of helical rim defects. J Plast Reconstr Aesthet Surg 2015;68:56-62.

29. Dresner H, Waselchuk E. Reconstruction of the middle third auricular defects. Oper Tech Otolaryngol Neck Surg 2017;28:114-8.

30. Zenn MR. Helical advancement with a posterior auricular pull-through flap: a technique for reconstruction of combined helical and scaphal defects. Aesthetic Plast Surg 1999;23:131-3. DOI PubMed

31. Patterson AR, Brady G, Walker PD, Telfer MR. The perichondrial cutaneous graft and "flip-flop" flap in facial reconstruction: a series of 41 cases. Br J Oral Maxillofac Surg 2008;46:114-8. DOI PubMed

32. Reddy LV, Zide MF. Reconstruction of skin cancer defects of the auricle. J Oral Maxillofac Surg 2004;62:1457-71. DOI PubMed

33. Dessy LA, Figus A, Fioramonti P, Mazzocchi M, Scuderi N. Reconstruction of anterior auricular conchal defect after malignancy excision: revolving-door flap versus full-thickness skin graft. J Plast Reconstr Aesthet Surg 2010;63:746-52. DOI PubMed

34. Li D, Xu F, Zhang R, et al. Surgical reconstruction of traumatic partial ear defects based on a novel classification of defect sizes and surrounding skin conditions. Plast Reconstr Surg 2016;138:307e-16e. DOI PubMed

35. Chattopadhyay D, Gupta S, Murmu MB, Guha G, Gupta S. Revisiting Gavello's procedure for single-stage reconstruction of the earlobe: the vascular basis, technique and clinical uses. Can J Plast Surg 2012;20:e22-4. PubMed PMC

36. Watson D, Hecht A. Repair of auricular defects. Facial Plast Surg Clin North Am 2017;25:393-408. DOI PubMed 